\title{
French Horn---All Rounder in the Orchestra
}

\author{
Yang LI \\ Wuhan University of Technology \\ Wuhan Conservatory of Music \\ Hubei, Wuhan,430000, China
}

\begin{abstract}
This article describes the various roles undertaken by the French horn in an orchestra and analyses the use of the French horn in orchestral music work in and before the twentieth century, and concluded the important function of the French horn, this article has a referential meaning to the reader who is interested in the French horn .
\end{abstract}

Keywords-French horn, orchestra, melody, tone

\section{INTRODUCTION}

The French horn is multifunctional in the orchestra. Firstly, the French horn "can show surprising flexibility in diversity of tone", it can be applied to perform different kinds of formal melody, harmony and statement". Secondly, it can merge various kinds of instrumental music parts together. C . Vasilenko points out in "The orchestration of symphony": "Special attention shall be paid to the autistic assimilation ability of the French horn, it is also a problem to merge its sound with other instruments especially with the woodwind".

The compositions selected in this article is by purpose. There are two reasons accounting for this : Firstly, Choose a familiar work from many kinds of orchestra work. Secondly, select the work in a comparative music style, such as the work with classic style or work with romantic style etc.

\section{THE SOFT PEDAL IN THE ORCHESTRA}

The tone of the French horn is slightly soft, its sound can merge well with other instruments. This opinion is presented in many orchestration textbooks. Whatever melody, harmony or counterpoint piano, the French orchestra can always play together with any musical instrument of orchestra.

The audio of the French horn has the same function as a soft pedal in the orchestra, which makes the audio of the orchestra more resounding. This audio blending characteristic allows the audio of each instrumental music well integrated, which achieves an effect of "Half the work with double results" :It makes the orchestra audio with 50 people achieve the likeness sound effect of 100 people. This audio was applied many times in orchestral music works in the classic-romantic period. The orchestration technology in this period was developed in the writing principles of fourparts, the emphasis on the harmony, blending within the parts,. Composers always use the "The tonal bridge" to coordinate the tone of each instrument, makes it "achieving mastery through a comprehensive study" .The French horn often plays a role as "bridge" in copper pipe ,wooden pipe and string music.

\section{OUTSTANDING MELODY PERFORMER}

Composers always pay a lot attention to the function of the French horn part in an orchestra, they usually make the French horn part of the performer of the melody, highlighting the audio of the French horn part by using the technology of tone intensity etc. The fantastic highlighted character of this audio in the French horn part is : On the one hand, it can be captured by audiences accurately and easily. On the other hand, this audio does not have "penetrating power" which above the whole orchestra, at the same time, there is no need to worry that this audio will cause bad integration effects with other instrument parts. Such as in 140 -144 sections, fourth chapter of the "Ninth symphony" which was written by Dvorak, the French horn part holds the post of melody performer. Its sound is very prominent, it can be captured accurately. At the same, the "soft" of this audio is also being highlighted, and fusing well with other instrument parts.

In truth, it is very difficult to instruct this audio by using technical words, therefore, why not use some visual language, describe the prominent audio of French horn parts from another angle: It is like the presentation of a wise man, although the tone is not high, but it blinks with the light of wisdom, leaves a deep impression in our memory; Or it is like a speech presented by a brilliant politician, impassioned, inspiring, however, the expression of language is naturally close to "The public" forming a good "interaction" with them.

\section{THE USE OF NEW MUSIC IN THE 20TH CENTURY.}

One of the important principals for the orchestra in 20th century is " Keep and strengthen several of the most instruments or instrumental tone and character to achieve the highest effect of tone". This article describes the use of the French horn in the music of the 20th century, based on the second principle.

The orchestration style of orchestral music in the 20th century has been converted from : "Sound integration" into "sound separation". Composers favor the individuation of each part of the tone in vertical structure, advocating the "dispersion" and "comparison" in each audio part of the orchestra, so that the "separation" of the whole sound of the orchestra can be formed, this is the starting point of the orchestral procession for many composers in the 20th century. However, what's the purpose for composers in the 
20th century using the orchestral method of "audio separation" ? Following are the relative explanations presented by Schoenberg and Varese.

Schoenberg, one of the most important composers in the 20th century has one point that : "The main part for my orchestrate is of solo, in most cases, although there are many parts, it is still stuffy-----This kind of orchestration, does not comes from fondness, but it is a hope that each part can be given color, so that it can keep its own characteristic when mixing together other parts. I believe that, a kind of sound, although its sharp but very clear can be achieved by using this method. It has realized one of my principles: all of the things written must be heard by others "another outstanding composer Varese in the 20th century, his understanding is more "go straight to the heart of the matter", he says :" Regarding the problem of audio characteristic , my standpoint is opposite to the symphony. The symphony orchestra strives to achieve the most blend of color, but I devote on the huge distinction between color and density, to make the audience can recognize ".From this, composers apply the orchestration method of "sound separation" to make the audiences can recognize each autistic part and the tone of various instruments.

The orchestra technology of French horn has changed a lot in this period, it also serves as an independent part, separate with other instrumental parts in audio, which makes everyone can be heard."

In the 32-36 sections of the first chapter in "violin concerto" which was written by Berger, the French horn was the only brass instrument that performed, and it has a huge distinction regarding tone with woodwind instrument ,string instruments and harp, which ensures the tonal independent of French horn to a large extent.

\section{CONCLUSIONS}

In conclusion, this article analyzed the different roles undertaken by French horn in orchestra and the usage of
French horn which is representative in orchestral works in $20^{\text {th }}$ century and its before, described the function of French horn which is an important instrument in orchestra, expecting it can generate a certain reference meaning to the readers who are interested in French horn.

\section{ACKNOWLEDGEMENT}

The article is excerpted from "The Acoustic Characteristics and Processing Technology of the Horn Part in the Orchestra"which is the author's thesis for m.s.

[1] Written by Gao Hongxiang, "Basic course of orchestration", People's Music Publishing House, the first version in March, 2002, page 155.

[2] Written by Zhen Yinglie, "Writing base of ordered music", Shanghai Publishing House, the first version in December 1989, page 108

[3] Written by Yang Liqing, "Summary of the historical evolution of the orchestral instruments style", "Music Art", Publish in installments from 1-6, 1986

[4] Written by Peng Zhimin, "Analysis Course of New Musical Works ”, Hunan literature and art publishing house, version 2004.

[5] Writtern by Peng Zhimin, "Basic Course of Musical Analysis", People's Music Publishing House, the first version, September 1997.

[6] Written by Zheng Yinglie,"Writing base of ordered music", Shanghai Publishing House, version 1989.

[7] Written by Gardner Read, "Style and Orchestration", A Division of Macmillan Publishing Co.Inc, version 1979.

[8] Written by Samuel Adler, "The Study of Orchestration", George J. Mcleod Limited, Toronto, version 1982. 